\title{
Parque Nacional Serra da Canastra (Minas Gerais - Brasil): proposta de painel interpretativo
}

\author{
Serra da Canastra National Park (Minas Gerais - Brazil): Interpretative panel proposal
}

\author{
Lilian Carla Moreira Bento \\ Professor doutora do Instituto de Ciências Humanas do Pontal \\ Universidade Federal de Uberlândia \\ $\underline{\text { liliancmb@ufu.br }}$ \\ Thallita Isabela Silva Martins Nazar \\ Doutora em Geografia - IG/UFU \\ thallitamartins09@gmail.com
}

\begin{abstract}
Resumo
O Parque Nacional Serra da Canastra é uma unidade de conservação integral localizada no sudeste do Estado de Minas Gerais, Brasil. Apesar desse tipo de unidade prever a visitação, não existe na área de estudo nenhum plano de interpretação ambiental que garanta aos visitantes o entendimento dos locais. Diante disso, o objetivo deste trabalho foi propor um painel interpretativo para a Cachoeira Casca D'Anta, visto ser um dos atrativos mais visitados e, portanto, ter maior potencial de utilização. O painel proposto foi elaborado a partir de um plano interpretativo que buscou responder alguns questionamentos norteadores, a saber: $i$ - o que interpretar? (temática a ser abordada), $i i$ - por que interpretar?, iii- público-alvo, $i v$ - como? (justificativa para o tipo de meio interpretativo escolhido) e $v$ - onde (localização do meio selecionado). O painel apresentado visa preencher uma lacuna do ponto de vista do entendimento, no que diz respeito a origem da cachoeira de Casca D'anta. Relevante destacar que se trata apenas de uma proposta e que sua implantação dependerá de recursos da gerência do parque.
\end{abstract}

Palavras-chave: interpretação ambiental, geodiversidade, geoconservação.

\begin{abstract}
Serra da Canastra National Park is an integral conservation unit located in the southeastern state of Minas Gerais, Brazil. Although this type of unit provides visitation, there is no environmental interpretation plan in the study area that guarantees visitors an understanding of the sites. Given this, the objective of this paper is to propose an interpretative panel for the Casca D'anta Waterfall, as it is one of the most visited attractions and, therefore, has more significant potential for use. The proposed panel was elaborated from an interpretative plan that sought to answer some guiding questions, namely: $i$ - what to interpret? (thematic to be addressed), ii- why interpret?, iii- target audience, $i v$ - how? (justification for the type of interpretive medium chosen) Furthermore, $v$ - where (location of the selected media). The panel presented aims to fill a gap from the point of view of understanding regarding the origin of the waterfall of Casca D'anta. It is essential to highlight that this is only a proposal and that its implementation will depend on resources of the park management.
\end{abstract}

Key-words: environmental interpretation, geodiversity, geoconservation. 


\section{INTRODUÇÃO}

O Parque Nacional da Serra da Canastra (PNSC) está localizado no sudeste de Minas Gerais e abrange os municípios de São Roque de Minas, Sacramento, Delfinópolis, São João Batista do Glória, Capitólio e Vargem Bonita. Sua área total é de 197.787 hectares, porém, deste total apenas 71.525 se encontram com situação fundiária regularizada, estando sob o domínio do Instituto Chico Mendes de Conservação da Biodiversidade - ICMBio (Figura 1).

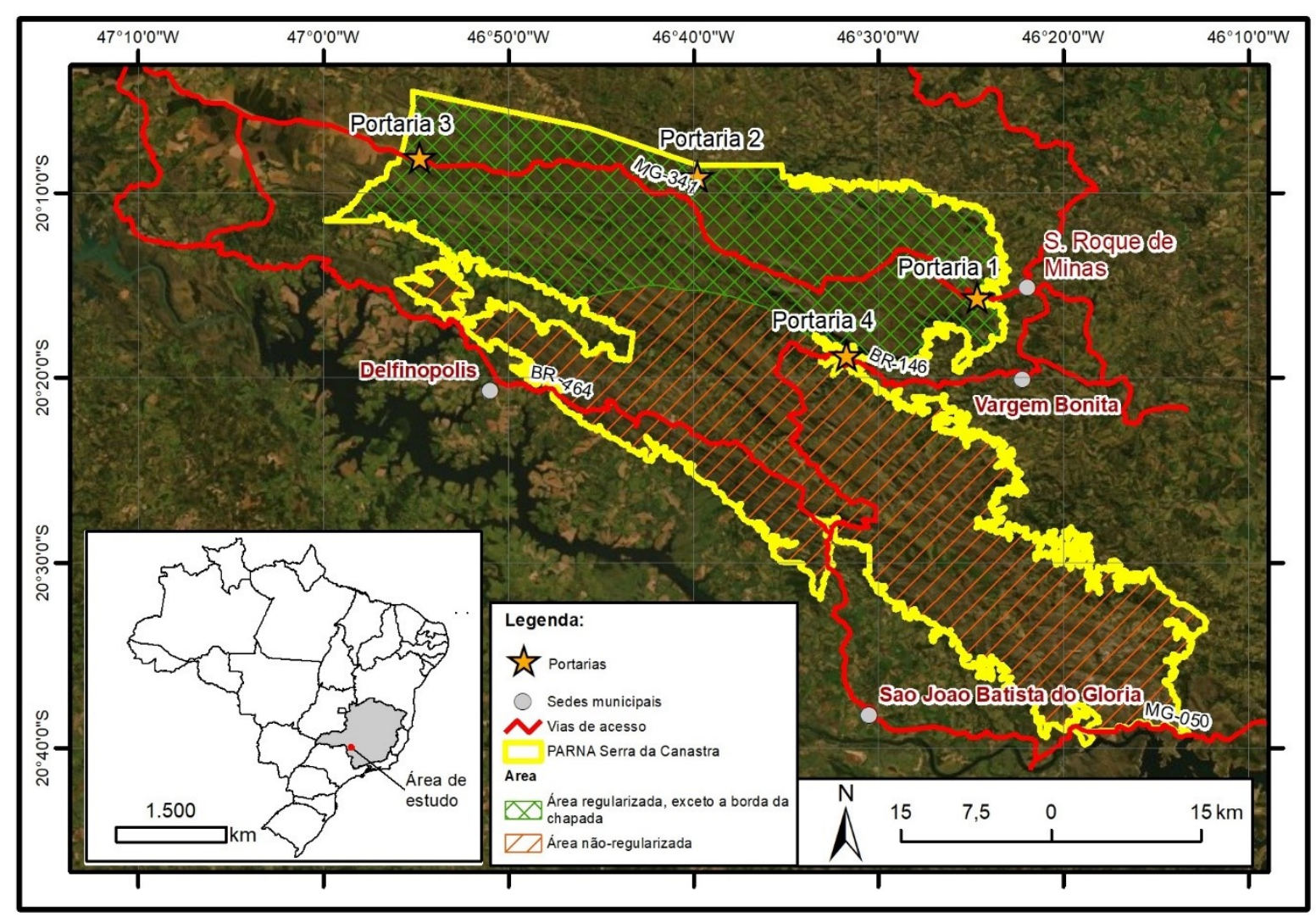

Figura 1 - Localização do Parque Nacional Serra da Canastra

Fonte: Autoras, 2019.

A origem dessa unidade de conservação, como consta no seu Plano de Manejo (IBAMA, 2005), tem correlação direta com problemas de secas associadas a desmatamentos e programas de reflorestamento da década de 1970, os quais poderiam comprometer a bacia do rio São Francisco. Tal situação acabou impulsionando diversas campanhas de preservação das nascentes do rio São Francisco, culminando com a criação do parque em 3 de abril de 1972, pelo Decreto $\mathrm{n}^{\circ} 70.355$.

O PNSC é uma das categorias de unidades de Proteção Integral do Sistema Nacional de Unidades de Conservação (Lei Federal 9.985/2000) que prevê o uso indireto dos recursos naturais, mediante atividades, tais como pesquisa e visitação. Além dos objetivos de conservação ambiental, essas áreas devem cumprir sua função sociocultural, a qual está relacionada com os programas de educação e interpretação ambientais (BENTO, 2014). 
O PNSC recebeu, em média, 61 mil visitantes nos últimos oito anos, sendo o parque com maior visitação no Estado de Minas Gerais no ano de 2018 (Figura 2). Apesar de índices tão elevados, ele não possui, atualmente, nenhum tipo de programa de educação e interpretação ambiental, levantando a questão de uma possível subutilização da visitação, uma vez que tem se pautado apenas na contemplação.

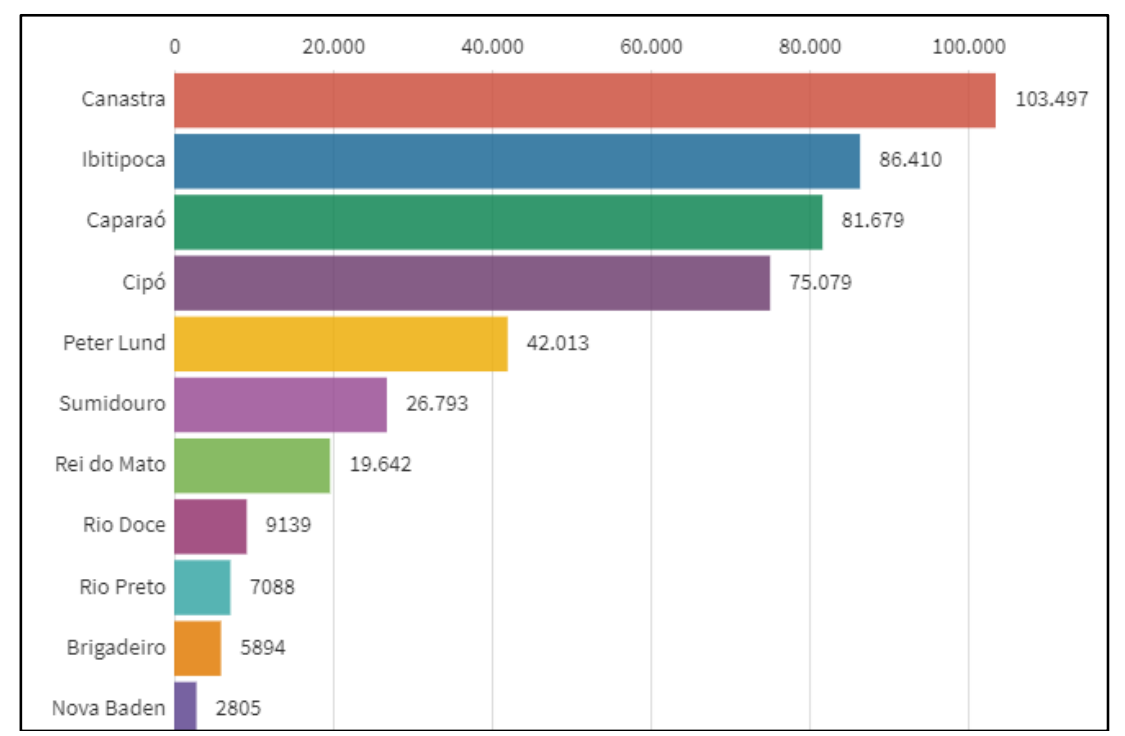

Figura 2 - Número de visitantes em parques de Minas Gerais no ano de 2018.

Fonte: Observatório do Turismo.

Alvarenga et al. (2018) corroboram que a estrutura, os equipamentos e, até mesmo o modo de operação do PNSC, mostram-se insuficientes para o uso educativo e cultural dos atrativos, sugerindo que eles devem ser equipados com estruturas (por exemplo, painéis interpretativos), além de outras estratégias, como cursos para os condutores, criação de trilhas autoguiadas, entre outros.

Foi essa realidade, aliada a grande beleza cênica e diversidade dos elementos da Geodiversidade, descrita por Machado e Azevedo (2015) como a variedade de estruturas e materiais que constituem o substrato físico natural e suporta a biodiversidade, que suscitaram o objetivo desse trabalho em contribuir com a interpretação ambiental do parque e, consequentemente, de aliar a apreciação com a sensibilização e a educação mediante a proposição de um painel interpretativo. A ideia do painel, dentre tantas opções de meios interpretativos, deve-se ao fato de não haver obrigatoriedade de acompanhamento de um guia ou monitor nas trilhas do parque.

\section{FUNDAMENTAÇÃO TEÓRICA}

Do latim interpretari, interpretar têm múltiplos significados, tais como determinar com precisão o sentido de um texto ou dar determinado sentido a alguma coisa. Trazida ao contexto ambiental, a interpretação teria o sentido de traduzir, de explicar a linguagem da natureza, de forma que as pessoas “[...] descubram um mundo que não tinham percebido antes" (VASCONCELOS, 
2006, p. 23). Tilden (1977) corrobora esse argumento ressaltando que "[...] os ambientes naturais não falam por si. O público em geral não entende a sua linguagem. Sua beleza e majestade necessitam de um interlocutor quando surgem as perguntas - o quê, como e por quê" (Apud VASCONCELOS, 2006, p. 23).

A interpretação ambiental não surgiu ao acaso, de acordo com Moreira (2008), seu aparecimento se deu nos Estados Unidos, já que alguns visitantes do Parque Nacional do Yelowstone estavam interpretando, erroneamente, um fenômeno geológico. A partir dessa situação começaram a ser organizadas visitas guiadas e folhetos explicativos nos parques nacionais, mas, ainda assim, perduravam alguns problemas. Na tentativa de revertê-los, Freedman Tilden lançou, em 1957, o livro "Interpreting our heritage", que é referência até os dias atuais.

Tilden definiu interpretação ambiental como "[...] an educational activity which aimsto reveal meanings and relationships through the use of original objects, by firsthandexperience, and by illustrative media, rather than simply to communicate factual information” (1957, p. 8). Mais tarde, ele atualizou essa definição e mudou o termo, educativo, para recreativo, tendo em vista que o objetivo principal da interpretação é transmitir uma mensagem leve, com algum significado, além de ser provocativa e induzir o visitante a querer saber mais, fugindo do caráter formal relacionado ao termo educativo (BENTO, 2014).

Após Tilden, pode-se encontrar novas referências estrangeiras nessa temática, Giacomo (2006) destaca as da National Countryside Commission (Inglaterra), de Don Aldridge (1973), de Sharpe (1976) e de Ham (1992). Atualmente há uma gama diversa de trabalhos acadêmicos e de instituições que concordam que, no geral, a interpretação ambiental deve ser encarada como uma forma de comunicação e tradução da natureza (COSTA; OLIVEIRA, 2018; DELGADO, 2000; MURTA; ALBANO, 2002; MINISTÉRIO DO MEIO AMBIENTE - MMA, 2006; FARIA; PIRES, 2007; URQUÍ; MARTINEZ; VALSERO, 2007; HAM, 2007; MENEGHINI; GUERRA, 2008; MACHADO, 2008; IKEMOTO, 2008; RODRIGUES, 2008; MIRANDA; 2008; IKEMOTO; MORAES; COSTA, 2009; FOLMANN; PINTO; GUIMARÃES, 2010, MINISTÉRIO DO TURISMO - MT, 2010; MOREIRA, 2012).

Essa tradução não é vazia de significado, no Brasil, ela vem ao encontro de uma demanda existente no seio das unidades de conservação abertas à visitação que é conciliar as necessidades dos visitantes sem comprometer a conservação da área (VASCONCELOS, 1998), devendo ser organizada através de programas de Educação/Interpretação ambiental. Essa demanda se assenta na ideia de que a existência de uma área protegida não é garantia de sua conservação; Miller (1997) considera que sua sobrevivência estará assegurada de fato apenas quando os visitantes e a comunidade local reconheceram a importância desses locais, tanto do ponto de vista ambiental, 
como cultural, econômico, entre outras possibilidades, sendo fundamental que sejam elaborados programas de Educação/Interpretação ambiental.

Pádua (1977) citado por Vasconcelos (1998) ratifica a importância desses programas ao afirmar que a criação das unidades de conservação não pode terminar com a publicação ou determinação do ato político, ao contrário, a existência dessas unidades depende do cumprimento da sua função sociocultural.

Programas de educação e interpretação ambiental são indispensáveis para que as unidades de conservação de todas as categorias de manejo, cumpram plenamente com sua função ambiental e social [...], eles funcionam como elos entre as áreas protegidas e o público, produzindo resultados importantes e necessários tanto para a conservação como para o desenvolvimento das pessoas [...] também podem gerar recursos financeiros, tanto para a unidade de conservação como para a região, auxiliando o desenvolvimento local integrado (VASCONCELOS, 2006, p. 78).

A interpretação ambiental é um instrumento básico na conservação e gestão do patrimônio. Ela é capaz de acrescentar valor ou realçar a experiência vivida no lugar, estimulando a apreciação ambiental, induzindo atitudes de respeito e proteção, além de promover entretenimento para os visitantes e, ainda, popularizar o conhecimento ambiental e sensibilizar as pessoas para que elas tenham atitudes preservacionistas em relação ao patrimônio (GIACOMO, 2006).

É preciso esclarecer que Educação e Interpretação ambiental são atividades que possuem objetivos educativos em comum, entretanto, elas atuam de forma distinta. Bento (2014) explica que a educação ambiental é um processo educativo contínuo e demorado, podendo acontecer em ambientes formais e não formais, enquanto a interpretação é uma atividade pontual direcionada à sensibilização do visitante, em ambientes não formais, destacando-se as áreas protegidas. Diante disso, a interpretação ambiental pode ser considerada como um instrumento da educação ambiental, uma vez que proporciona conhecimento sobre alguma coisa e visa à mudança de comportamentos considerados ambientalmente incorretos.

A interpretação ambiental é organizada em meios personalizados (quando há a presença de uma pessoa, um guia ou monitor ambiental, por exemplo, que vão acompanhar e traduzir os lugares para os visitantes) ou não personalizada (folhetos, placas, trilhas autoguiadas). No caso das placas, Vasconcelos (2006) chama atenção para o fato de que existem diferentes tipos que podem ser utilizadas em unidades de conservação, a saber: $i$ - Reguladoras (divulgar as normas, regras e precauções); ii- Informativas (informar as distâncias, nome dos lugares e infraestrutura); iiiIndicativas (indicar direções e distâncias) e, $i v$ - Interpretativas (explicar as características do local e seus significados). Mas apenas esta última pode ser considerada um meio interpretativo, pois é a única que reúne as informações necessárias à tradução dos ambientes, fugindo do mero aspecto informativo ou indicativo. 
A escolha do meio interpretativo depende das características da área e também deve fazer parte de um contexto mais amplo que é o planejamento da interpretação ambiental, o qual deve se basear num plano que é, segundo Verveka (1998), a base para uma interpretação estruturada e racional. Esse plano se baseia em cinco pilares principais, o primeiro diz respeito ao que será interpretado, ou seja, a escolha da temática da mensagem; o segundo reúne os objetivos dessa interpretação e se pauta em três categoria, a saber: $i$ - congnitivos - o que se pretende que as pessoas aprendam, ii- comportamentais - o que se pretende que as pessoas façam e iii- emocionais - que tipo de sensações se pretende estimular nos visitantes. O terceiro pilar é a escolha do público alvo, quem irá receber a mensagem e demanda um conhecimento prévio das características desse público, entretanto, quando isso não for possível há a possibilidade de, no quarto pilar, não se escolher apenas um tipo de meio interpretativo, mas uma diversidade maior objetivando atingir também um público mais heterogêneo. Por fim, no quinto pilar, onde e/ou quando se refere ao local ou locais que receberão os meios interpretativos e tal escolha está atrelada ao meio escolhido (Figura 3). Mesmo não aparecendo no plano, é preciso destacar a importância dos processos de avaliação, monitoramento e manutenção dos meios interpretativos, de forma que ele seja sempre revisto atentando às necessidades dos visitantes, a atualização dos conteúdos, deterioração dos materiais, dentre outros.

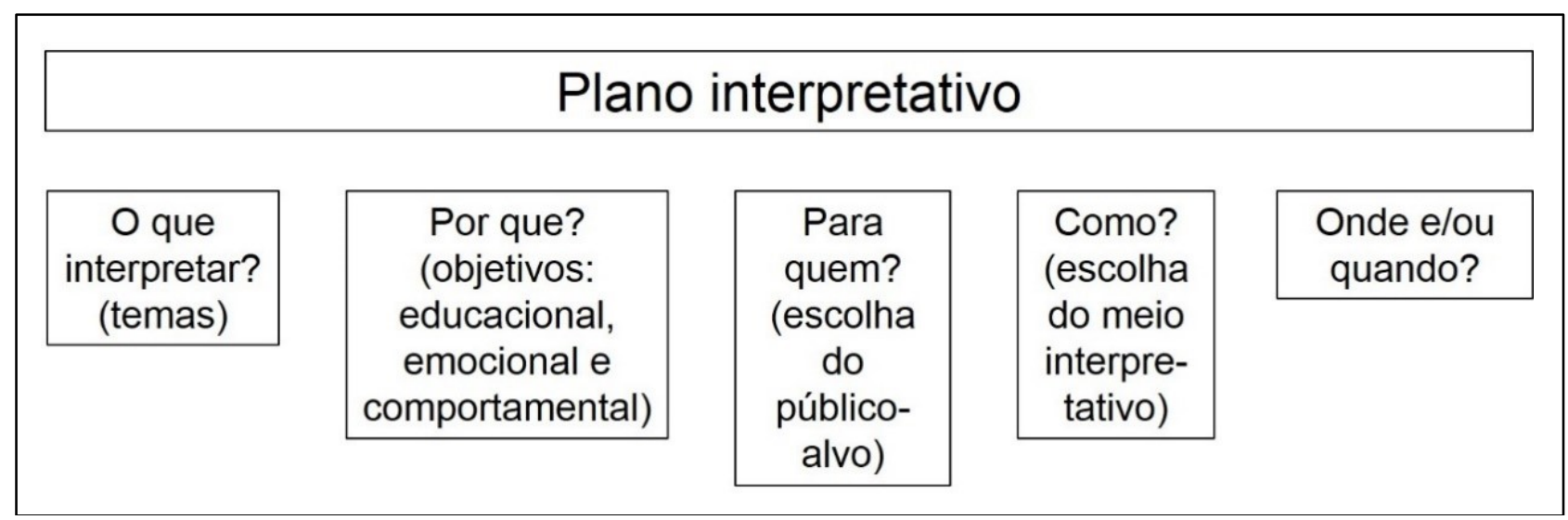

Figura 3 - Esquema geral de um plano interpretativo.

Fonte: Autoras, 2019.

O maior desafio da interpretação ambiental é traduzir um lugar, muitas vezes muito complexo do ponto de vista natural, como é o caso da Serra da Canastra, e levar essa mensagem até os visitantes. E o desafio não reside apenas no ponto de vista da informação, ou seja, traduzir um conhecimento científico complexo numa linguagem menos técnica, mais clara e que tenha algum sentido; mas fazer com que os visitantes se interessem por essa mensagem, pois estão numa atividade recreativa e, às vezes, não querem se desviar dessa atividade, ouvindo os guias ou lendo painéis. 
E é nesse ponto que a obra de Tilden se faz tão atual, pois ainda na década de 1950 conseguiu indicar alguns princípios que regem a abordagem da interpretação ambiental, de forma que a mesma seja realmente uma tradução. Aqui se faz pertinente destacar e refletir sobre dois destes princípios:

- A interpretação é uma forma de comunicação que vai além da informação, tratando dos significados e questionamentos, e o entendimento do ambiente demanda não apenas descrever a paisagem tal como ela se apresenta aos nossos olhos hoje. É importante apresentar ao visitante um universo muito maior que envolve o entendimento dos processos que geraram aquela paisagem, isto é, é direcionar o olhar para as feições, formas atuais, mas estimulando-os a vislumbrar o que ocorreu no passado. E, talvez, a partir desse entendimento do tempo da natureza, despertar o estado emocional e cognitivo desses visitantes, despertando uma afetividade e mudança de atitudes (MACHADO, 2008).

- O objetivo da interpretação não é a instrução, mas a provocação. Não cabe a interpretação ambiental, que ocorre nas áreas protegidas e de forma pontual, ensinar nada a ninguém, mas sim despertar pensamentos e as fazer refletir sobre questionamentos que antes não tinham, ressaltando aquilo que poderia parecer insignificante ou passar despercebido.

Os princípios formulados por Tilden podem ser sintetizados em três palavras: provocar (isso ocorre quando são introduzidas ideias através de uma linguagem mais clara e questionamentos), relacionar (usa analogias e metáforas para relacionar novos conceitos aos que os visitantes já sabem ou entendem) e revelar (deve-se revelar uma mensagem inesquecível: o que se quer que os visitantes recordem depois da visita?). Nesse último caso, convém citar o geológo Asier Hilario, diretor científico do Geoparque da Costa Basca (Zumaia - Espanha), segundo ele, os visitantes não devem apenas visitar uma bela paisagem, eles devem entender que estiveram num lugar espetacular e que se depararam com uma história que nunca teriam imaginado antes.

Quando você diz aos visitantes que essas camadas se formaram no fundo do mar, com cerca de mil metros de profundidade, escuras, mas cheias de vida, e que quando a Península Ibérica colidiu com o continente europeu e os Pirenéus subiram, esses fundos também foram levantados, você está descobrindo um mundo absolutamente novo para as pessoas. (HILÁRIO, 2018 apud YUSTE, 2018, p. 3, tradução nossa).

Para se chegar a esse deslumbramento o qual Hilário faz alusão, Ham (1992) destaca que, além dos princípios formulados por Tilden, a abordagem interpretativa precisa ser amena (agradável e com capacidade de captar a atenção), pertinente (a partir de dois aspectos, com mensagem compreensíveis e que, ao mesmo tempo, sejam relevantes aos visitantes), organizada (é preciso que 
siga uma ordenação lógica, com começo, meio e fim) e temática (a mensagem deve ter um tema claro e definido, o qual sintetiza a ideia principal da mensagem).

Mas quais as vantagens da inserção de programas de Educação e Interpretação ambiental nas unidades de conservação? Hoje em dia não é difícil encontrar pesquisas que apontam para essas vantagens e, inclusive, para a importância desses programas inserirem não apenas a temática da Biodiversidade como também da Geodiversidade. Esses benefícios podem ser sintetizados em três grandes áreas: 1- os visitantes e a comunidade local (enriquece a sua visita com um viés educativo, distanciando-se do aspecto meramente contemplativo; a partir do entendimento da área); 2- o lugar (contribui com sua a conservação, uma vez que só se protege aquilo que se conhece a importância e 3- as instituições (melhora a gestão e o aproveitamento educativo e recreativo) (CARVALHO, 2001; FARIA; PIRES, 2007; GIACOMO, 2006; GUIMARÃES, 2007; IKEMOTO, 2008; MACHADO, 2008; MENDONÇA, 2005; MMA, 2006; MOREIRA, 2011; MURTA; ALBANO, 2002; NEIMAN, 2007; MEIRA, BRITO, MORAIS, 2016).

\section{METODOLOGIA}

A metodologia adotada neste trabalho fundamentou-se nos pressupostos da pesquisa qualitativa, tendo como procedimentos metodológicos os trabalhos de gabinete (divididos em duas etapas, uma realizada antes e outra após a pesquisa de campo) e a pesquisa de campo. Esta última envolveu registro fotográfico e de coordenadas geográficas, bem como o preenchimento de uma ficha de caracterização dos atrativos do parque, em específico das quedas d'água localizadas na área regularizada. Essa ficha incluía alguns critérios de análise, tais como: $i$ - acessibilidade (se avaliou os parâmetros de distância do percurso, tempo de trilha, tipo de terreno e o desnível da trilha), $i i_{-}$ beleza cênica e iii- valores científico e educativo (foi considerada a existência de publicações científicas sobre as quedas), os quais indicassem o local com maior potencial para colocação do painel.

Em gabinete, a primeira etapa realizada foi a pesquisa bibliográfica, com levantamento de obras pertinentes ao estudo e a elaboração do painel interpretativo. Com relação a esse plano, o primeiro questionamento (o que interpretar?) foi pensado tendo em vista a opção em se trabalhar com quedas d'água e se preencher uma lacuna do ponto de vista do conhecimento, já que durante os trabalhos de campo foi recorrente ouvir dos visitantes questionamentos sobre a gênese destes locais. O segundo (por que?), se baseou em três objetivos: educacional (o que se quer que os visitantes saibam), emocional (o que se quer que os visitantes sintam) e comportamental (o que se quer que os visitantes façam). Em (para quem?), ou seja, na escolha do público-alvo, optou-se em considerar todos os visitantes do parque, um grupo bastante heterogêneo, por não existir na atualidade nenhum 
estudo do perfil do público que visita o parque. E, por fim, no item (como?), optou-se pelos painéis interpretativos em virtude das características da área de estudo, na qual o acesso aos atrativos pode ser feito por trilhas autoguiadas.

Tendo como ponto de partida esse plano, foi possível fazer a concepção do painel interpretativo, optou-se em usar um programa mais acessível, apesar de suas limitações, o Power point. É necessário esclarecer que não existe nenhum manual específico sobre elaboração de painéis interpretativos (BENTO, 2014), inclusive, Von Ahn e Simon (2109), analisaram 37 painéis de Geoparques da Organização das Nações Unidas para a Educação, a Ciência e a Cultura (UNESCO) e concluíram que não há nenhum tipo de padrão, em termos estruturais e técnicos, na elaboração dos painéis dispostos nesses locais. Nesse sentido, a parte de formatação e layout se basearam em alguns direcionamentos encontrados, principalmente, em Bento (2014); Fonseca (2010); Mansur e Nascimento (2007); Murta; Albano (2002); Pacheco (2012); Projeto Doces Matas (2002), Vasconcelos (1998) e Vasquez (2010):

i. Cores: optou-se em usar um esquema cromático formado por uma cor predominante e outras que ressaltam a predominante, harmonizando-se com ela. Segundo Heller (2012), a cor laranja é considerada a cor da diversão, da sociabilidade e do lúdico e pode ser combinada com as cores amarela, vermelha, azul e verde, optou-se em usar o laranja com o amarelo. As condições de luz também interferem, em locais expostos ao sol, os painéis devem ter fundo escuro e letras claras, já num local mais sombreado, letra escura sobre um fundo mais claro, como é o caso em questão.

ii. Formato: painéis interpretativos podem ser dispostos na forma de mesa de leitura (inclinação de 600 para trás) ou na posição vertical. Para não atrapalhar a visão de outros aspectos, o painel proposto deverá ser retangular e no formato de mesa de leitura, com tamanho de 140 $\mathrm{x} 70 \mathrm{~cm}$.

iii. Materiais: podem ser utilizados madeira, ferro galvanizado e alumínio, fibra de vidro, aço inox, cerâmica e acrílico. Sua escolha depende de fatores variados como condições climáticas, durabilidade, estética e custo, ficando tal decisão a cargo da gerência do parque, responsável por sua confecção, colocação e manutenção.

iv. Texto: optou-se em colocar justificado, com espaço entrelinhas e a fonte usada foi a Garamond. É necessário padronizar o tamanho da fonte nos painéis, sugere-se: títulos (tamanho 60), textos (tamanho 52 com espaço entre os parágrafos de 50), legenda explicativa (tamanho variando de 28 a 32) e fonte das imagens (tamanho 24).

v. Elaboração do texto: os textos devem ter mensagens curtas e imagens explicativas dos conceitos abordados. Sugere-se o uso de títulos e questionamentos atrativos, que evocam algum tipo de memória afetiva e, principalmente, que consigam provocar e revelar elementos que não são evidentes para todos os visitantes, tais como trechos de letras de música. 
vi. Uso de imagens: é recomendado o uso apenas de 50\% de texto, o restante do espaço deve ser empregado na colocação de imagens. Em todos os painéis faz-se necessário a colocação de mapas com a distribuição dos geossítios do parque, bem como da localização do visitante. Esquemas explicativos e fotos do parque também devem ser inseridos no intuito de aguçar a curiosidade, bem como facilitar o entendimento de determinados conceitos empregados.

\section{CARACTERIZAÇÃo da ÁREA de ESTUDO}

\subsection{Aspectos da Geodiversidade}

Geodiversidade é um conceito análogo ao de Biodiversidade e que engloba a variedade de elementos abióticos, tais como os minerais, rochas, solos, relevo e paisagens, entre outros, assim como os processos que deram origem aos mesmos. Neste trabalho, o foco maior serão os aspectos geológicos e eles serão descritos numa linguagem menos técnica e mais genérica, uma vez que é possível encontrar vasta bibliografia que busca o entendimento da área numa perspectiva mais aprofundada (ANDRADE, 2012; ALKMIN, 2018; ALVARENGA et al., 2018; CHAVES; BENITEZ; ANDRADE, 2008; CARNEIRO et al., 2012; CORTES, 2015; HASUI, 2010, 2012; NAZAR, 2018; SAADI, 1991; SILVA, 2018; SIMÕES, 1995; UHLEIN et al., 2012; VALADÃO, 1998).

Bento e Rodrigues (2019) em “Aspectos geológicos e geomorfológicos da Cachoeira de Casca D'anta (Parque Nacional da Serra da Canastra - Minas Gerais, Brasil): primeiros passos para o seu aproveitamento geoturístico", fizeram um apanhado da história geológica e geomorfológica da Serra da Canastra. Segundo eles, essa serra é fruto de uma longa história geológica e da atuação de agentes geológicos internos e externos. Essa história teve início no final do Proterozoico, com a união de alguns continentes antes separados por um oceano, dando origem ao supercontinente Gondwana, associado a um ciclo tectônico, denominado de Ciclo Brasiliano. Essa colisão acarretou deformações diversas, tais como: orogenia com surgimento dos cinturões orogênicos, falhamentos, foliação e formação de rochas metamórficas. Essas deformações contribuíram, portanto, para a constituição de uma área topograficamente mais elevada e de grande complexidade litológica e estrutural, onde se encontra a Serra da Canastra, dentre outros exemplares ao longo do território brasileiro.

Tal complexidade litológica se deve, como destacado no artigo "Serra da Canastra: de mar a montanha", de autoria de Moraes e Seer (2015), ao fato de que parte das rochas encontradas no parque e arredores, como os quartzitos, filitos e os calcários - associadas, respectivamente, aos Grupos Canastra e Bambuí (Figura 4), nada mais são do que antigos terrenos que estavam submersos e foram expostos e/ou transformados pelo processo de metamorfismo ocasionado pela formação do Gondwana. 

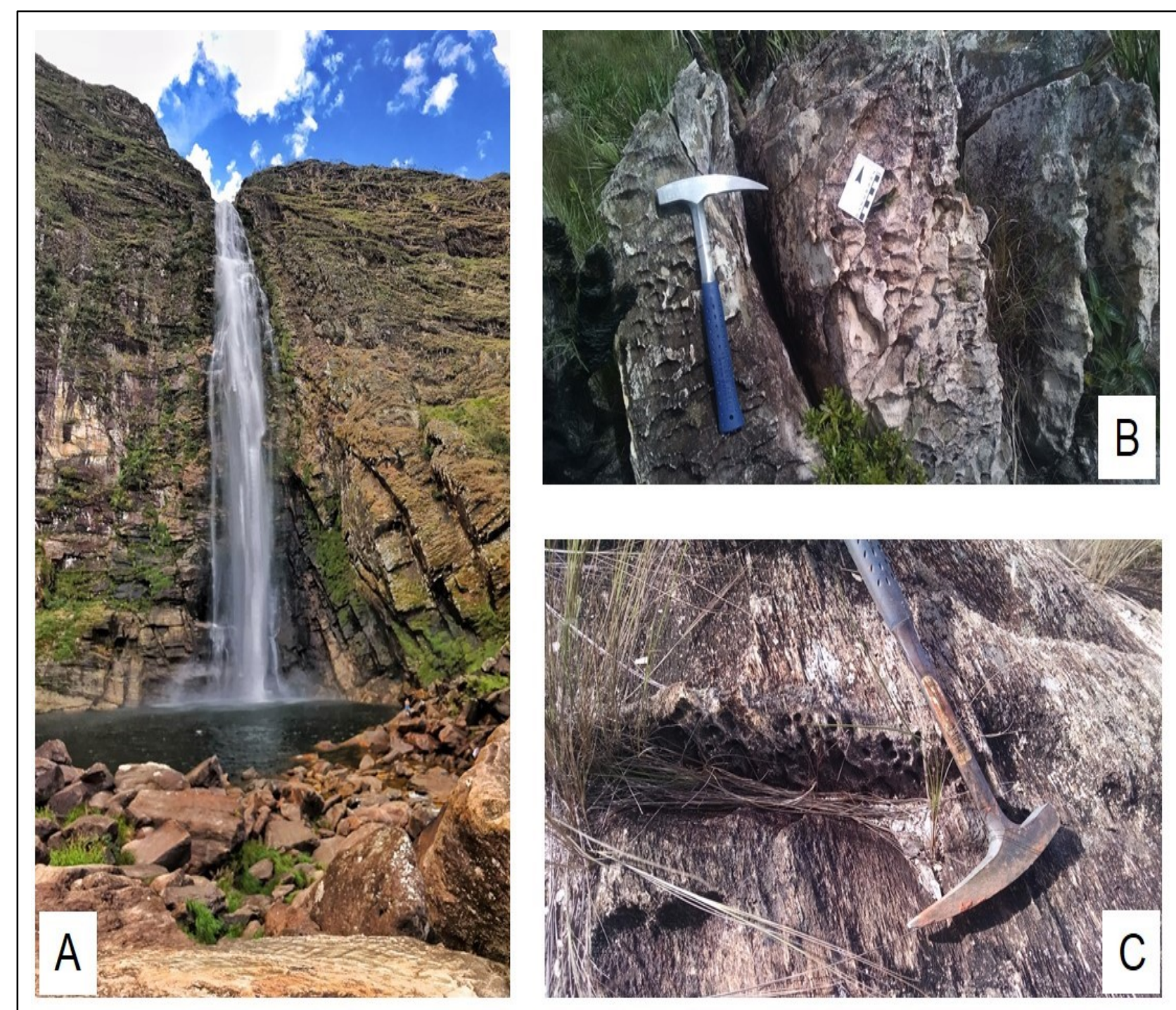

Figura 4 - Mosaico com características da rocha quartzítica encontrada no parque: A- Cachoeira Casca D'Anta - Parte baixa. Em primeiro plano, observa-se os blocos quartzíticos coluviais. Em segundo, a exuberância da queda d'água, guiada pelo paredão rochoso, B- Quartzito com presença de dissolução da sílica e com fratura extensional. Localizado na porção Leste do Chapadão do Diamante, em relevo de Cristas Quartzíticas e C- Quatzito micáceo localizado na porção Oeste do Chapadão do Diamante, em área de transição do relevo de Cristas Quartzíticas para relevo ondulado

Fonte: Autoras, 2019.

Em grande área do parque predomina o Grupo Canastra, destacando-se os quartzitos puros a micáceos. Segundo Bento e Rodrigues (2019) esses quartzitos apresentam camadas de espessuras variadas, podendo ser maciças ou laminadas. Nesse último caso, os minerais se recristalizam segundo direções preferenciais e formam planos de fraqueza no sentido perpendicular aos esforços e, sendo assim, os quartzitos micáceos, com esse tipo de clivagem, tendem a ser frágeis e apresentam a propriedade de se desagregarem em placas (Figura 5).

A separação do Gondwana, já no final do Triássico e no ciclo tectônico atual, produziu efeitos importantes sobre a área em questão a partir da intrusão de kimberlitos, reativação e geração de fraturas, além de influenciar na rede de drenagem, formando cânions e as quedas d'água (BENTO; RODRIGUES, 2019, NAZAR; RODRIGUES, 2019 a e b, SOUZA; RODRIGUES, 
2014). Desde então, até os dias atuais, a ação geológica dos agentes externos, mediante os processos de erosão, tem modelado a superfície e originado formações mais recentes, as coberturas detríticolateríticas, constituídas, no geral, por cascalho, areia, argila e óxidos e hidróxidos de ferro.

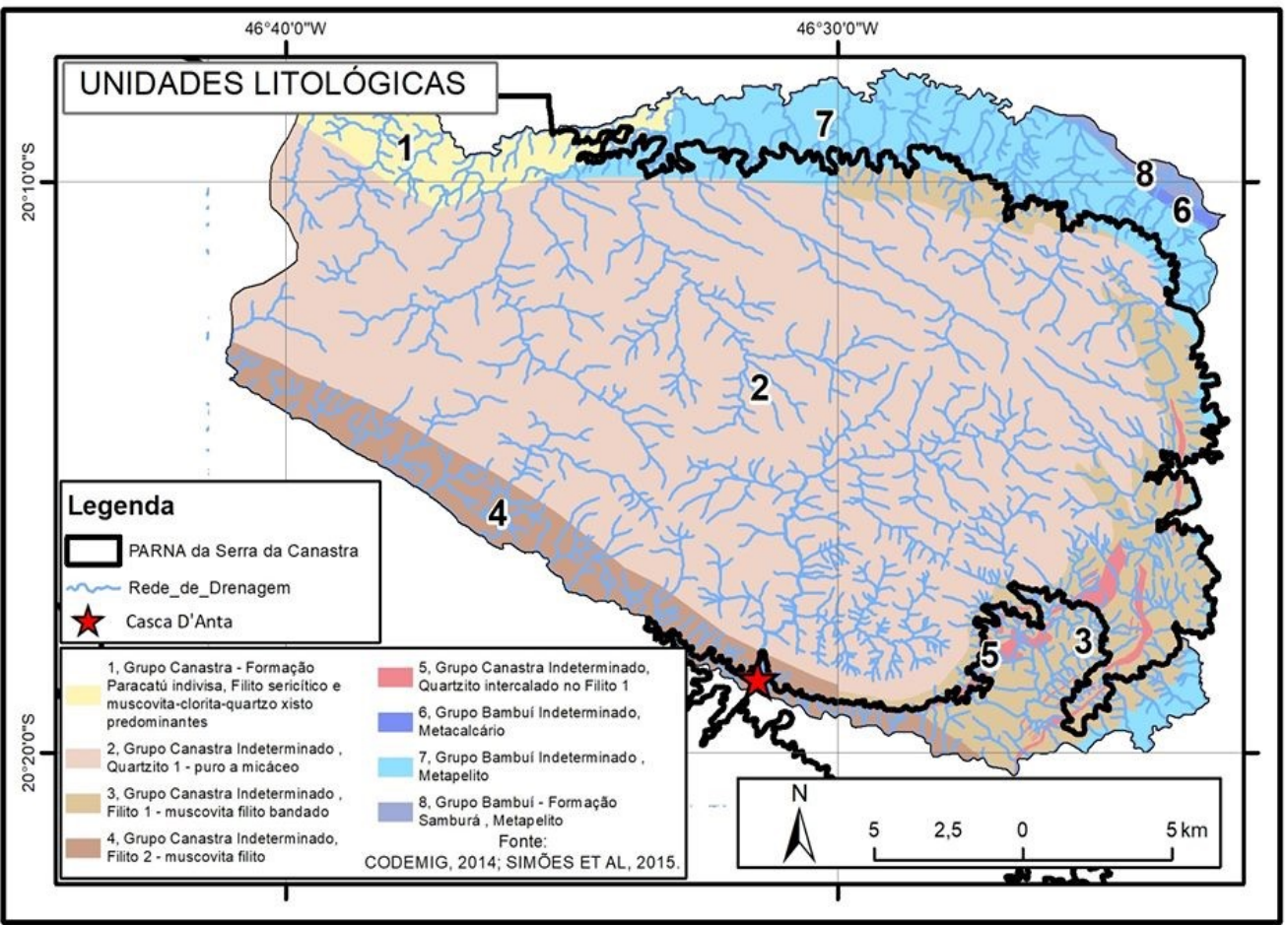

Figura 5 - Mapa das unidades litológicas do PNSC Fonte: Autoras, 2019.

A Serra da Canastra, com seus diversos compartimentos topográficos, é o resultado da ação de agentes geológicos internos e externos ao longo do tempo geológico e se destaca topograficamente, até os dias atuais, por conta do processo de erosão diferencial, isto é, os quartzitos do tipo puro a micáceos, encontrados no topo da chapada, são mais resistentes do que as rochas encontradas no seu entorno, mantendo-se imponente e gerando grande deslumbramento em todos aqueles que por ela passam (Figura 6).

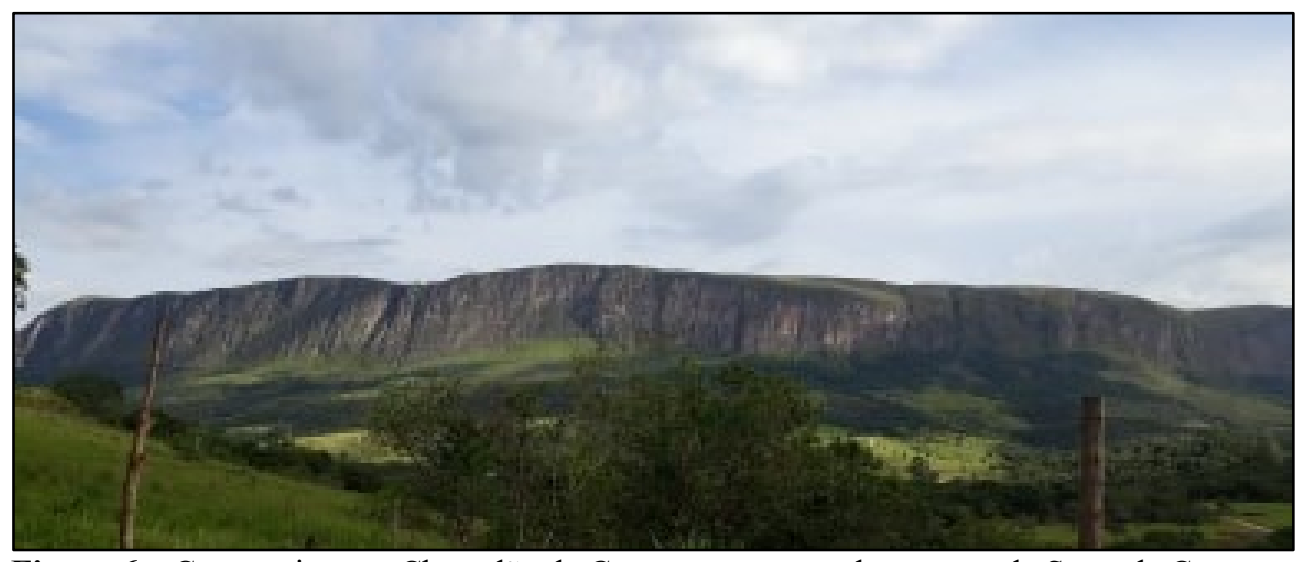

Figura 6 - Compartimento Chapadão da Canastra, encontrado no topo da Serra da Canastra em sua porção oriental, como resultado da erosão diferencial por sustentar os quartzitos puro a micáceos do Grupo Canastra (Fonte: Autoras, 2019). 


\section{RESULTADOS E DISCUSSÃO}

Existem quatro quedas d'água localizadas na área regularizada do parque e que estão abertas à visitação (Figura 7), entretanto, a que apresentou maior potencial para a interpretação, em virtude dos critérios descritos na metodologia, foi a Cachoeira Casca D’Anta.

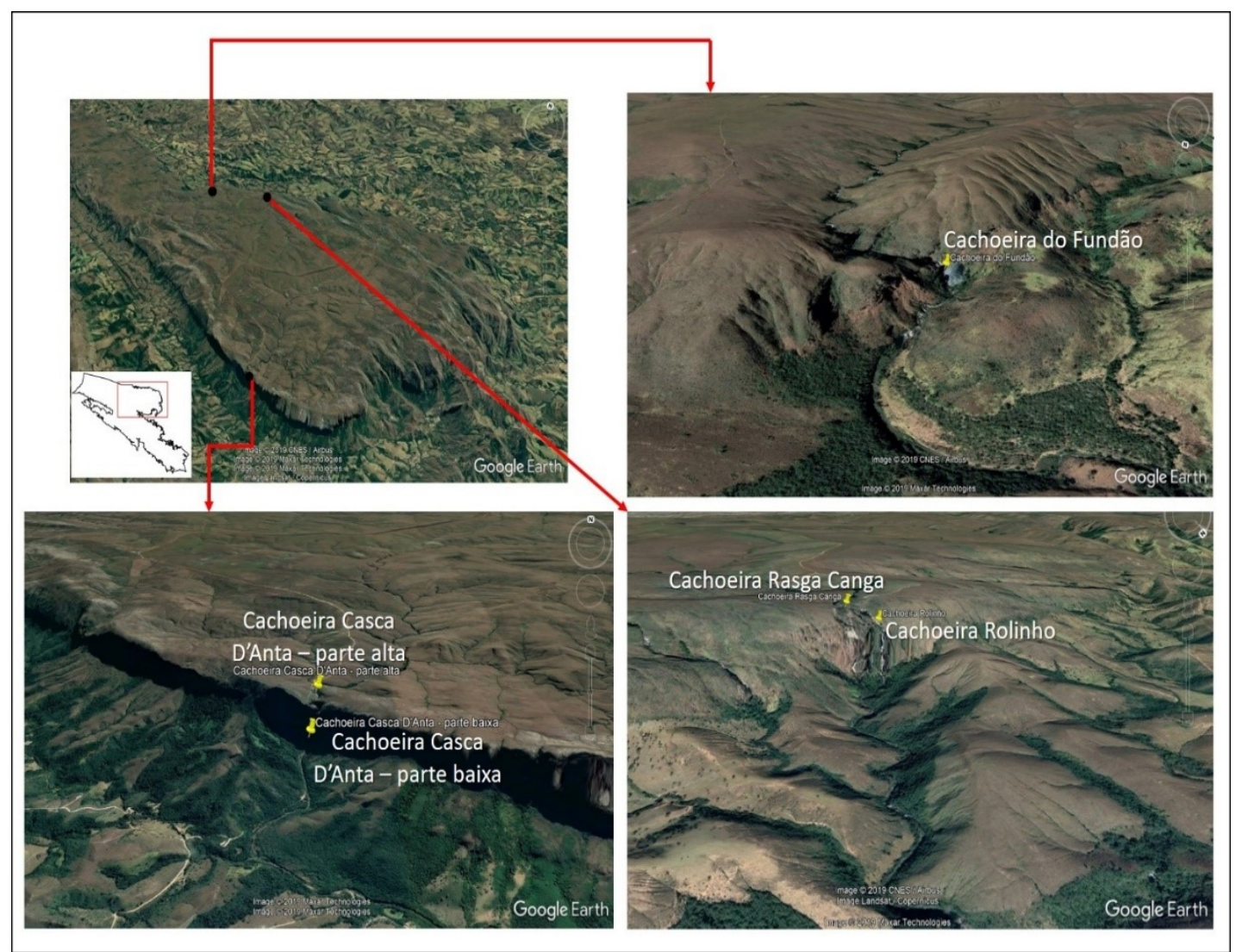

Figura 7 - Imagem de satélite destacando as quedas d'água abertas à visitação no PNSC. Fonte: Autoras, 2019.

A Cachoeira Casca D’Anta é uma queda de aproximadamente 200 metros (CHAVES; BENITEZ; ANDRADE, 2008), esculpida em quartzitos e que tem a sua gênese associada a existência de uma falha de empurrão, a qual originou no relevo um degrau por onde a água do rio São Francisco despenca verticalmente e forma uma feição de grande beleza cênica. A existência dessa falha é um dos resultados da longa história geológica a qual a região foi submetida, refletindo a ação dos agentes geológicos internos e externos, sendo este o tema central escolhido na composição do plano interpretativo (Tabela 1).

No que diz respeito ao texto do painel interpretativo, o título principal é o trecho da música Água de cachoeira, conhecida pela interpretação da cantora brasileira, Maria Bethânia: "Lá na pedreira, rola da cachoeira uma água forte pra me banhar, uma água forte pra me banhar...", já fazendo alusão a ação da água como importante agente geológico externo. Todavia, apenas a água não é um agente capaz de originar uma queda do tamanho da Casca D’Anta, o que dá abertura para 
mencionar outros temas, como a evolução geológica da área ao longo do tempo geológico, com destaque para os agentes internos.

Tabela 1 - Plano interpretativo elaborado para o Geossítio Cachoeira Casca D’Anta.

\begin{tabular}{|c|c|}
\hline $\begin{array}{l}\text { O que interpretar? (escolha do } \\
\text { tema central) }\end{array}$ & Origem da cachoeira de Casca D'anta. \\
\hline \multicolumn{2}{|l|}{ Por quê? (objetivos) } \\
\hline $\begin{array}{l}\text { 1- De aprendizagem: o } \\
\text { que se pretende que } \\
\text { eles compreendam? }\end{array}$ & $\begin{array}{l}\text { Que a paisagem é fruto de uma evolução que ocorreu ao longo do tempo } \\
\text { geológico, com a atuação de processos geológicos internos e externos. }\end{array}$ \\
\hline $\begin{array}{l}\text { 2- De emoção: o que se } \\
\text { pretende que eles } \\
\text { sintam? }\end{array}$ & $\begin{array}{l}\text { Respeito e admiração, pois todos os atrativos do parque retratam o trabalho } \\
\text { incessante dos agentes geológicos ao longo de um tempo muito longo. }\end{array}$ \\
\hline $\begin{array}{l}\text { 3- De comportamento: o } \\
\text { que se pretende que } \\
\text { eles façam? }\end{array}$ & $\begin{array}{l}\text { Que se sintam motivados a proteger não só os atrativos do PNSC, mas } \\
\text { elementos da natureza de outras localidades, tornando-se multiplicadores } \\
\text { do conhecimento adquirido. }\end{array}$ \\
\hline Quem? (público-alvo) & Visitantes e turistas que frequentam o parque (grupo heterogêneo). \\
\hline $\begin{array}{l}\text { Como? (seleção dos meios } \\
\text { interpretativos) }\end{array}$ & $\begin{array}{l}\text { Painéis interpretativos - o acesso a parte baixa da cachoeira ocorre } \\
\text { mediante trilhas autoguiadas, suscitando a necessidade de meios } \\
\text { interpretativos que garantam o entendimento dos locais visitados, uma vez } \\
\text { que não existe a figura de um guia ou monitor. }\end{array}$ \\
\hline Onde? (local para instalação) & $\begin{array}{l}\text { Mirante que dá acesso a cachoeira (parte baixa) - local estratégico, pois } \\
\text { permite visualizar a queda mesmo para as pessoas que não conseguirem } \\
\text { terminar a trilha e ter acesso às informações. }\end{array}$ \\
\hline
\end{tabular}

Fonte: Autoras, 2019.

O painel proposto é composto por uma mensagem principal e, baseado nela, foram indicados textos e imagens secundárias. $\mathrm{O}$ texto central foi escrito numa linguagem simples, como se estivesse conversando com o visitante, de maneira que o mesmo se sinta motivado a terminar a leitura e compreender um pouco a mensagem ali deixada (Figura 8).

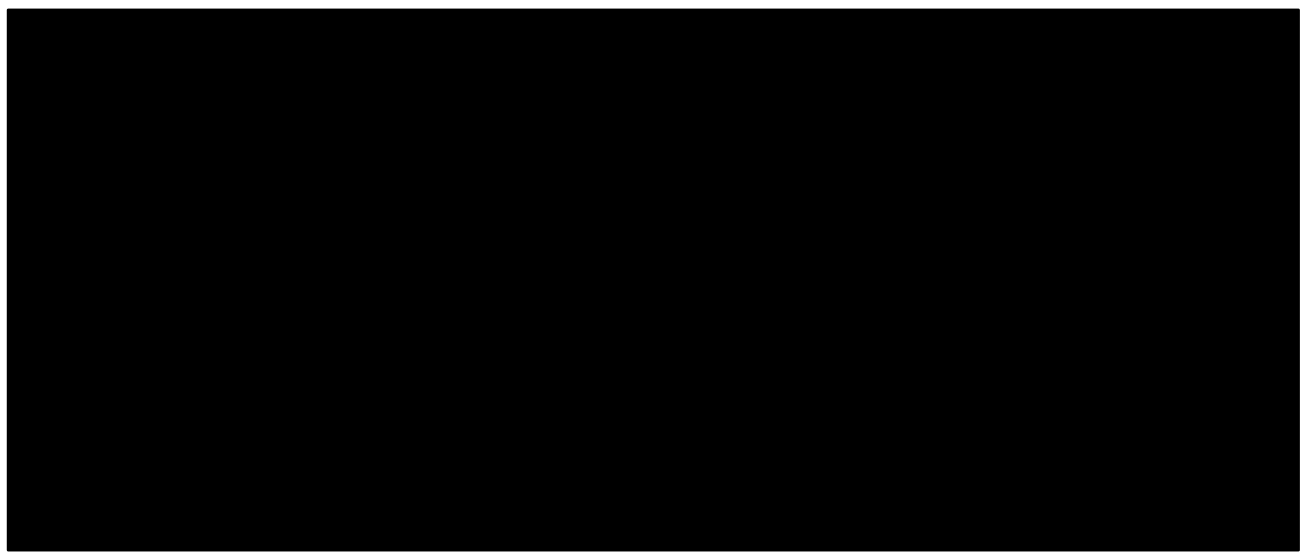

Figura 8 - Extrato do texto principal do painel interpretativo proposto para a área de estudo. Fonte: Autoras, 2019. 
A partir deste texto norteador foram inseridas outras mensagens, de acordo com as chamadas das imagens (Figuras 1-A, B, C e D). A primeira figura é um mapa mostrando a localização dentro do parque e alertando para a existência de outros atrativos a serem visitados (Figura 9), incentivando o visitante a conhecer esses locais.

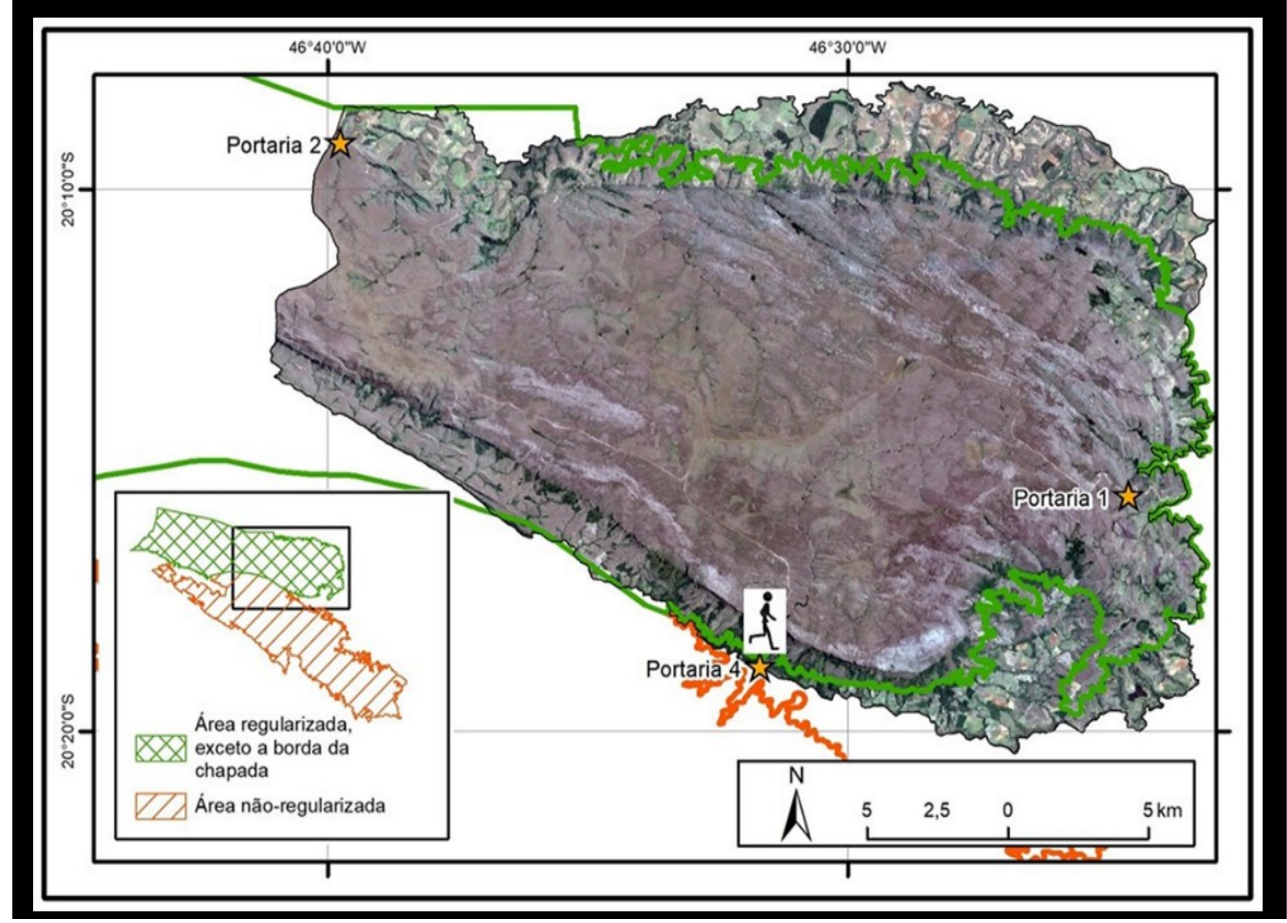

Figura 9 - Mapa destacando a localização do visitante na Cachoeira Casca D’Anta. Fonte: Autoras, 2019.

A origem dessa cachoeira está vinculada a existência de uma falha geológica e, desse modo, a Figura 1-B traz uma explicação sobre essa temática e, para ilustrar, foram colocadas três imagens, a saber: $i$ - os tipos principais de falhas geológicas, $i i$ - imagem de satélite destacando a falha onde se encontra a Cachoeira Casca D'Anta e iii- uma escarpa (Figura 10).

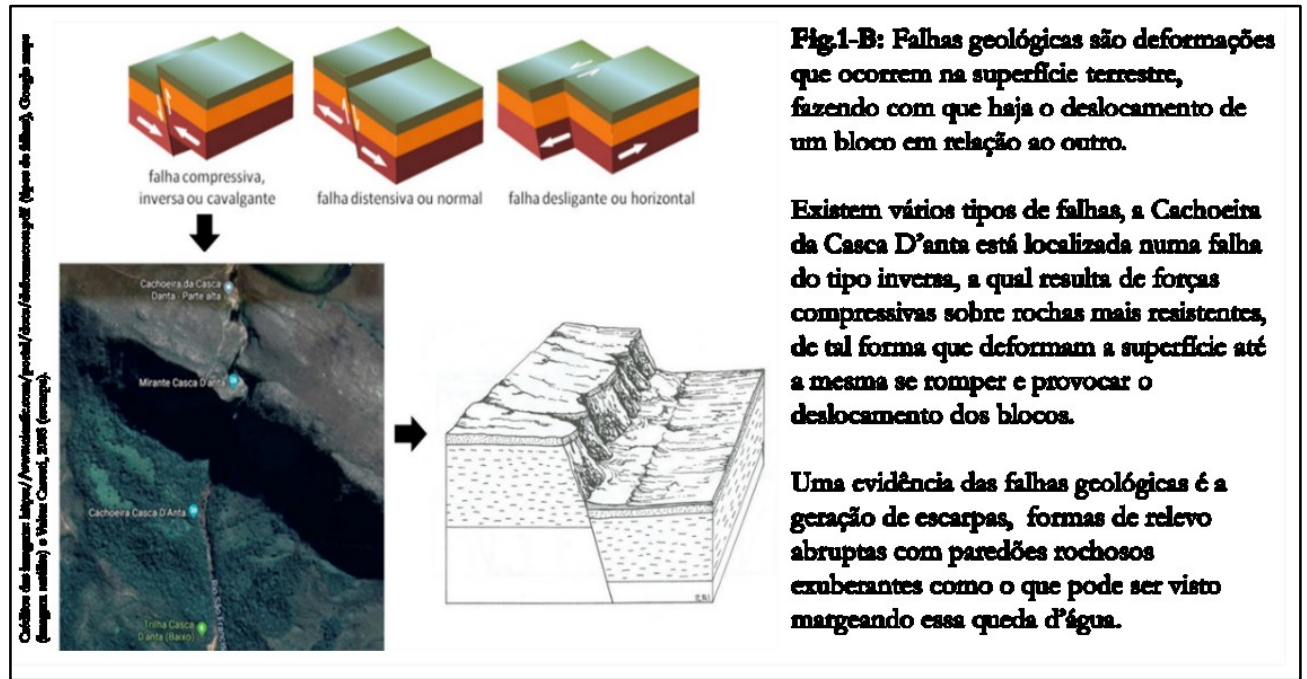

Figura 10 - Extrato do painel interpretativo explicando a formação das falhas geológicas. Fonte: Autoras, 2019. 
Já as figuras $1 \mathrm{C}$ e D tiveram por finalidade explicar a evolução geológica a qual essa região foi submetida, trazendo um questionamento provocativo que é: você sabia que a Serra da Canastra já foi mar? A primeira é a escala do tempo geológico, dando ênfase aos principais acontecimentos geológicos e seus reflexos na serra em questão. E, a outra, é um bloco diagrama mostrando como ocorreu a formação do supercontinente Gondwana e, consequentemente, dos cinturões orogênicos, para facilitar o entendimento dos visitantes quanto ao fato da Serra da Canastra já ter sido mar, como foi colocado no painel (Figura 11).

Todas essas informações, atentando ao plano interpretativo e a formatação escolhida, resultaram no painel proposto para a Cachoeira Casca D'Anta (Figura 12). O entendimento da origem dessa queda demanda um conhecimento maior que abarca a evolução geológica que a área foi submetida, por isso, foram colocadas informações não só do que é uma falha geológica ou como a mesma foi formada, como também o contexto geológico que propiciou a formação de tal feição. Se trata de uma temática ampla e complexa e cada frase e figura foram colocadas de modo cuidadoso, almejando que os visitantes passem a olhar com curiosidade e respeito para os elementos da Geodiversidade, tal como já o fazem para os elementos da Biodiversidade. 

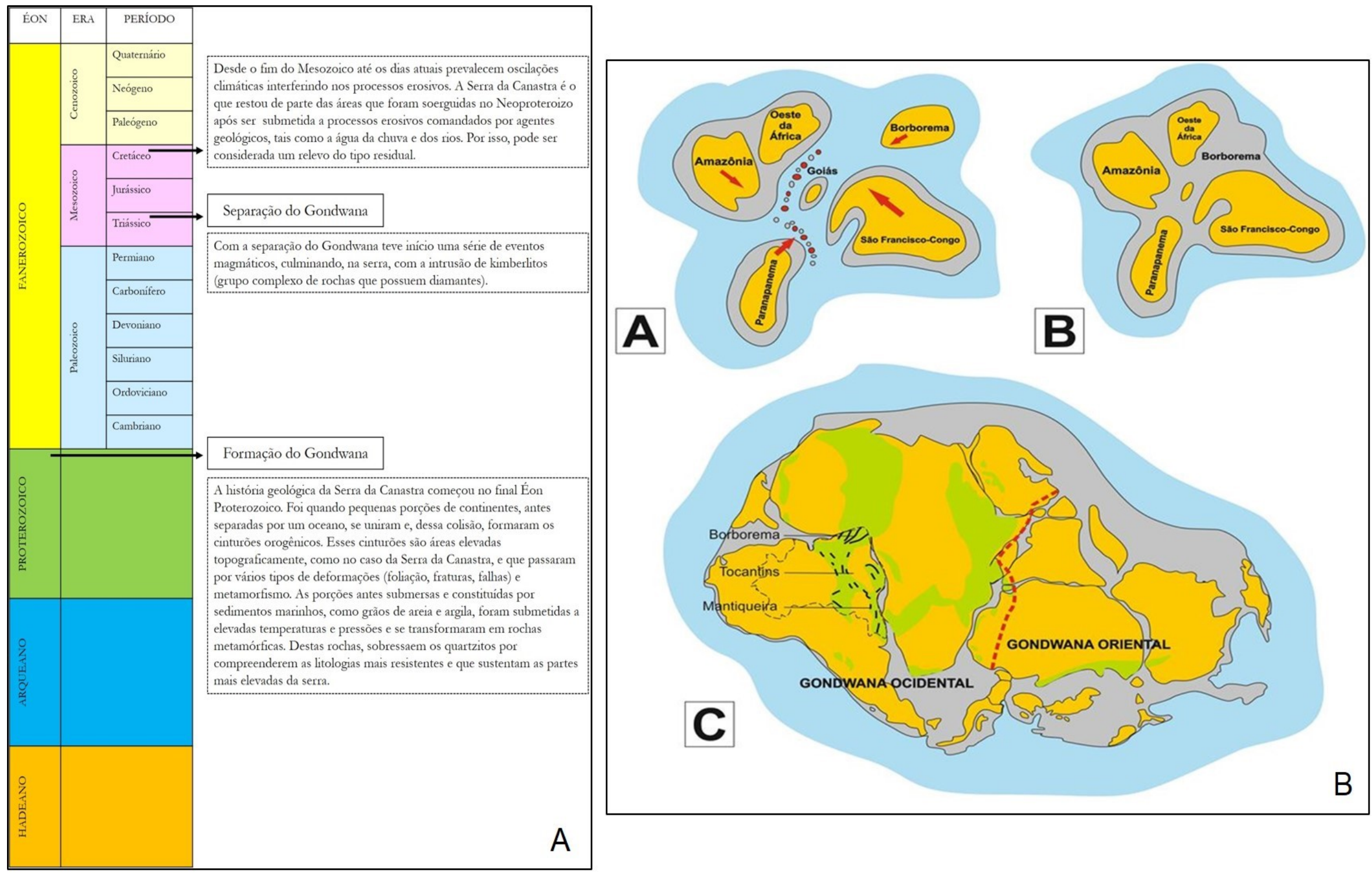

A

Figura 11 - Texto explicativo do painel proposto, sobre a evolução geológica da Serra da Canastra: A- Escala do tempo geológico destacando os principais acontecimentos que possibilitaram a formação e evolução da Serra da Canastra e B- Bloco diagrama mostrando a formação do supercontinente Gondwana e a formação dos cinturões orogênicos. Fonte: Autoras, 2019. 


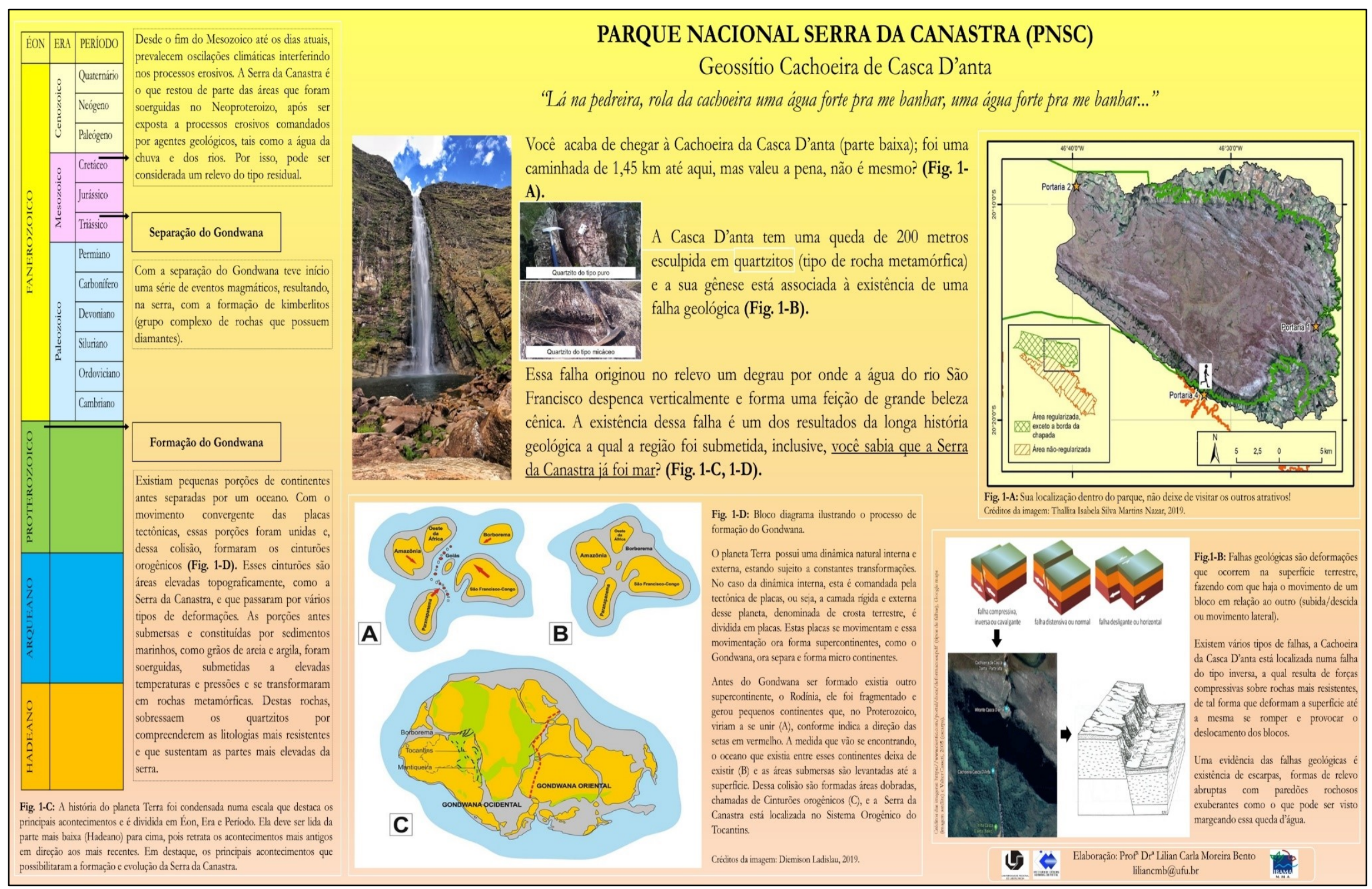

Figura 12 - Painel interpretativo elaborado para o Geossítio Cachoeira Casca D’Anta Fonte: Autoras, 2019. 


\section{CONSIDERAÇÕES E PERSPECTIVAS FUTURAS}

A Cachoeira Casca D'Anta é um dos atrativos mais visitados no PNSC e não é difícil imaginar o porquê disso: é um local de fácil acesso e com grande beleza cênica, atraindo o olhar de quem passa por aquela localidade. Mesmo estando numa unidade de conservação integral e sendo alvo de grande visitação, esse atrativo não conta com nenhum tipo de ferramenta que possibilite ao visitante o entendimento de sua formação, sinalizando para uma subutilização do ponto de vista do conhecimento.

Diante de tal realidade, o objetivo deste trabalho foi propor um painel interpretativo para a Cachoeira Casca D’Anta, tendo como ponto de partida a elaboração de um plano que norteou toda a sua elaboração, destacando as temáticas que seriam trabalhadas. Elaboração essa marcada por alguns desafios, entre eles:

- O PNSC é muito rico, tanto do ponto da Geodiversidade como da Biodiversidade e, mesmo com o plano interpretativo, os autores tiveram dificuldades, no início, de serem fiéis ao tema proposto.

- A área de estudo tem uma história geológica muito longa e complexa.

- Traduzir a linguagem científica, principalmente do conhecimento geológico, para uma linguagem mais acessível e, ainda, atrativa, não é uma tarefa fácil, pois, no geral, não é assim que se aprende.

Apesar de tais desafios, o objetivo foi atingido e a metodologia empregada, em especial a elaboração de um plano interpretativo, foi fundamental para obter êxito, pois o plano dá um direcionamento a partir de quatro eixos, a saber: escolha do tema, objetivos (de aprendizagem, emoção e comportamento), público alvo e localização.

A proposição desse painel é uma contribuição dos autores à gestão do parque, no que diz respeito a necessidade de se criar programas de educação e interpretação ambiental, de modo que as visitas agreguem um viés educativo. Como futuras contribuições e reflexões, destaca-se três demandas: $i$ - elaborar novos meios interpretativos para a temática aqui apresentada, de forma a se atingir um número maior de visitantes, sendo de suma importância capacitar os guias e monitores que atuam no parque. O ICMBIo já promoveu uma capacitação incluindo a temática da Geodiversidade, no entanto, dada a riqueza da área e complexidade da temática, esse tipo de ação deve ser continuada; ii- propor painéis para outras temáticas, tais como a relação entre a Biodiversidade e a Geodiversidade, dentre outros e iii- apresentar o plano proposto para direção do parque e solicitar a confecção e manutenção do mesmo, bem como a criação e inserção de um $Q R$ 
Code para que os visitantes possam acessar o painel por dispositivos móveis e ter um tempo maior para assimilar as informações nele contidas.

\section{AGRADECIMENTOS}

O presente trabalho foi realizado com apoio da Fundação de Amparo à Pesquisa do Estado de Minas Gerais - FAPEMIG, assim, agradecemos pelo fomento concedido através do projeto CRA APQ-0231/2016.

\section{REFERÊNCIAS}

AlVARENGA, L. J.; CASTRO, P. de T. A.; BERNARDO, J. M.; CAMPOS, I. C. de. Paisagem Cultural e Geoconservação: Contributos Conceituais Aplicados na Serra da Canastra, Brasil. Anuário do Instituto de Geociências, Rio de Janeiro, v. 41, n. 2, p. 241-251, 2018.

ALKMIN, F. F. História geológica de Minas Gerais. In: PEDROSA-SOARES, A. C.; VOLL, E.; CUNHA, E. C. (Orgs.). Recursos minerais de Minas Gerais On Line: síntese do conhecimento sobre as riquezas minerais, história geológica, e meio ambiente e mineração de Minas Gerais. Belo Horizonte: CODEMGE, 2018. p. 1-37.

ANDRADE, K. W. Química de minerais indicadores de intrusões kimberlíticas com ênfase na província diamantífera Serra da Canastra (MG): importância na prospecção de intrusões férteis. 2012. 174 f. Dissertação (Mestrado em Geologia) - Instituto de Geociências, Universidade Federal de Minas Gerais, Belo Horizonte, 2012.

BENTO, L. C. M. Parque Estadual do Ibitipoca/MG: potencial geoturístico e proposta de leitura do seu geopatrimônio por meio da interpretação ambiental. 2014. 185 f. Tese (Doutorado em Geografia) - Instituto de Geografia, Universidade Federal de Uberlândia, Uberlândia, 2014.

BENTO, L. C. M.; RODRIGUES, S. C. Aspectos geológicos e geomorfológicos da Cachoeira de Casca D'anta (Parque Nacional da Serra da Canastra - Minas Gerais, Brasil): primeiros passos para o seu aproveitamento geoturístico. In: ENCONTRO LUSO-BRASILEIRO DE PATRIMÓNIO GEOMORFOLÓGICO E GEOCONSERVAÇÃO, 3,. 2019. Guimarães. Anais... Guimarães: CEGOT, 2019. P. 17.

CARNEIRO, C. D. R.; ALMEIDA, F. F. M. De; HASUI, Y.; ZALÁN, P. V.; TEIXEIRA, J. B. G. Estágios evolutivos do Brasil no Fanerozoico. In: HASUI, Y.; CARNEIRO, C. D. R.; ALMEIDA, F. F. M. De; BARTORELLI, A. (Orgs.). Geologia do Brasil. São Paulo: Beca, 2012. p. 131-137.

CARVALHO, I. C. M. Educação ambiental: a formação do sujeito ecológico. 5 ed. São Paulo: Cortez, 2011. 255p.

CHAVES, M. L. S. C.; BENITEZ, L.; ANDRADE, K. W. Cachoeira Casca d'Anta, São Roque de Minas: berço do Velho Chico, o rio da integração nacional. In: WINGE, M. (Org.). Sítios geológicos e paleontológicos do Brasil. Brasília: CPRM, 2008. p. 151-162.

CORTES, J. P. S. Compartimentação e Evolução Geomorfológica da Borda Ocidental da Serra da Canastra - MG. 2015. 130 f. Dissertação (Mestrado em Geociências e Meio Ambiente) - 
Instituto de Geociências e Ciências Exatas, Universidade Estadual Paulista Júlio de Mesquita Filho, Rio Claro, 2015.

COSTA, N. M. C.; OLIVEIRA, F. L. Trilhas: "caminhos" para o geoturismo, a geodiversidade e a geoconservação. In: GUERRA, A. J. T.; JORGE, M. do C. O. (Orgs.). Geoturismo, geodiversidade e geoconservação: abordagens geográficas e geológicas. São Paulo: Oficina de Textos, 2018. p. 201-227.

DELGADO, J. A interpretação ambiental como instrumento para o ecoturismo. In: SERRANO, C. (Org.). A educação pelas pedras - ecoturismo e educação ambiental. São Paulo: Chronos, 2000. p. 155-169.

FARIA, H. H.; PIRES, A. S. Atualidades em gestão de unidades de conservação. In: ORTH, D.; DEBETIR, E. (Orgs.). Unidades de conservação - gestão e conflitos. Florianópolis: Insular, 2007. p. 11-41.

FOLMANN, A. C.; PINTO, M. L. C.; GUIMARÃES, G. B. Trilhas interpretativas como instrumentos de geoturismo e geoconservação: caso da Trilha do Salto São Jorge, Campos Gerais do Paraná. GeoUERJ, Rio de Janeiro, v. 2, n. 21, p. 239-267, 2010.

FONSECA, C. O. Faces de paisagem: interpretação para valorização do geoturismo no Parque Estadual Serra do Rola Moça - MG. 2010. 83 f. Monografia (Trabalho de Graduação em Turismo) - Instituto de Geociências, Universidade Federal de Minas Gerais, Belo Horizonte, 2010.

GIACOMO, V. Z. Interpretação como instrumento para a educação patrimonial: Complexo da Praça da Liberdade. 2006. 90 f. Monografia (Trabalho de Graduação em Turismo) - Instituto de Geociências, Universidade Federal de Minas Gerais, Belo Horizonte, 2006.

GUIMARÃES, S. T. L. Paisagens: aprendizados mediante as experiências - um ensaio sobre interpretação e valorização da paisagem. 2007. 160 f. Tese (Doutorado em Geografia) - Instituto de Geociências e Ciências Exatas, Universidade Estadual Paulista, Rio Claro, 2007.

IKEMOTO, S. M. As trilhas interpretativas e sua relevância para promoção da conservação. Trilha do Jequitibá, Parque Estadual dos Três Picos (PETP), RJ. 2008. 121 f. Dissertação (Mestrado em Ciência Ambiental) - Instituto de Geociências, Universidade Federal Fluminense, Niterói, 2008.

IKEMOTO, S. M.; MORAES, M. G.; COSTA, V. C. Avaliação do potencial interpretativo da trilha do Jequitibá, Parque Estadual dos Três Picos, Rio de Janeiro. Sociedade e Natureza, Uberlândia, v. 21, n. 3, p. 271-287, dez. 2009.

HAM, S. Interpretacion ambiental: uma guia pratica para gente com grandes ideas y presupuestos pequenos. Colorado: North. Am. Press, 1992. 437p.

HASUI, Y. Sistema Orogênico Tocantins. In: HASUI, Y.; CARNEIRO, C. D. R.; ALMEIDA; F. F. M., BARTORELLI, A. Geologia do Brasil. São Paulo: Beca, 2012. p. 289-330.

HASUI, Y. A grande colisão pré-cambriana do Sudeste brasileiro e a estruturação regional. Geociências,São Paulo, v. 20, p. 141-169, 2010.

HELLER, E. A psicologia das cores - como as cores afetam a emoção e a razão. 1. ed. São Paulo: GG, 2012, 311 p. 
IBAMA. Plano de Manejo do Parque Nacional da Serra da Canastra. Brasília: IBAMA, 2005. 799 p. Disponível em: $<$ http://www.icmbio.gov.br/portal/images/stories/imgs-unidades coservacao /PM_PNSC_Resumo_Executivo.PDF $\geq$ Acesso em: 03 abr. 2017.

MACHADO, A. C. A. R. Ecoturismo na Serra do Caraça: contribuições da interpretação para a conservação ambiental. 2008. 71 f. Monografia (Trabalho de Graduação em Turismo) - Instituto de Geociências, Universidade Federal de Minas Gerais, Belo Horizonte, 2008.

MACHADO, M. M.; ÚRSULA, R. Essa tal de Geodiversidade... Revista UFMG, Belo Horizonte, v. 22, n. 1 e 2, p. 182-193. 2015.

MANSUR, K. L.; NASCIMENTO, V. M. R. Popularización del conociemento geológico: metodologia del proyecto "Caminhos geológicos". Enseñanza de las Ciencias de la Tierra, Espanha, v. 15, n. 1, p. 77-84, 2007.

MEIRA, S. A.; BRITO, D. S.; MORAIS, J. O. de. Interpretação ambiental e Geodiversidade: proposta de painel interpretativo sobre o Geossítio Pedra Furada, Parque Nacional de Jericoacoara, Ceará. Espaço Aberto, Rio de Janeiro, v. 6, n. 2, p. 9-27, 2016.

MENDONÇA, R. Conservar e criar: natureza, cultura e complexidade. São Paulo: Editora SENAC SP, 2005. 255p.

MENGHINI, F. B.; GUERRA, A. F. S. Trilhas interpretativas: caminhos para a educação ambiental. In: SEMINÁRIO DE PESQUISA EM EDUCAÇÃO DA REGIÃO SUL, 7., 2008. Itajaí. Anais... Itajaí: UNIVALI, 2008. p. 15.

MILlER, K. A Evolução do Conceito de Áreas Protegidas no Mundo. In: CONGRESSO BRASILEIRO DE UNIDADES DE CONSERVAÇÃO, 1997. Curitiba. Anais... Curitiba: UNILIVRE, 1997. p.3-21.

MMA. Diretrizes para visitação em unidades de conservação. Brasília: MMA, 2006. 61p. Disponível em: <http://www.mma.gov.br/estruturas/ascon_boletins/_arquivos/livro.pdf>. Acesso em: 27 abr. 2012.

MINISTÉRIO DO TURISMO. Ecoturismo: orientações básicas. 2. ed. Brasília: MT, 2010. 92p.

MIRANDA, J. M. La interpretación del patrimonio tiene que ver com significados. 2008. Textos de docência. Mensagem recebida por<liliancmb@yahoo.com.br>em 23 abr. 2012.

MORAES, L. C; SEER, H. J. Serra da Canastra: de mar a montanha. Ciência Hoje, v. 55, n. 328, p. 25-29, 2015.

MOREIRA, J. C. Patrimônio geológico em Unidades de Conservação: atividades interpretativas, educativas e geoturísticas. 2008. 428 f. Tese (Doutorado em Geografia) - Centro de Filosofia e Ciências Humanas, Universidade Federal de Santa Catarina, Florianópolis, 2008.

MOREIRA, J. C. Interpretação ambiental, aspectos geológicos e geomorfológicos. Boletim de Geografia, Maringá, v. 30, n. 2, p. 87-98, 2012.

MOREIRA, J. C. Geoturismo e interpretação ambiental. Ponta Grossa: Editora da UEPG, 2011. $157 \mathrm{p}$. 
MURTA, S. M.; ALBANO, C. (Orgs.). Intepretar o patrimônio - um exercício do olhar. Belo Horizonte: Editora UFMG, 2002. 288p.

NAZAR, T. I. S. M. O. Chapadão do Diamante na Serra da Canastra/MG, Brasil: caracterização geomorfológica e análise integrada do meio físico a partir de dados multifontes. 2018. 270 f. Tese (Doutorado em Geografia) - Instituto de Geografia, Universidade Federal de Uberlândia, Uberlândia, 2018.

NAZAR, T. I. S. M.; RODRIGUES, S. C. Relevo do Chapadão do Diamante, Serra da Canastra/MG, Brasil: compartimentação e análise a partir dos aspectos geomorfométricos. Revista Brasileira de Geomorfologia, v. 20, p. 69-88, 2019a. http://dx.doi.org/10.20502/rbg.v20i1.1300

NAZAR, T. I. S. M.; RODRIGUES, S. C. Mapeamento e Análise de Geocoberturas no Chapadão do Diamante - MG - Brasil. Mercator, Fortaleza, v. 18, p. 1-19, 2019b. http://dx.doi.org/10.4215/rm2019.e18010.

NEIMAN, Z. A educação ambiental através do contato dirigido com a natureza. 2007. $177 \mathrm{f}$. Tese (Doutorado em Psicologia) - Instituto de Psicologia, Universidade de São Paulo, São Paulo, 2007.

OBSERVATÓRIO DO TURISMO. Visitação em parques nacionais. 2019. Disponível em: $<$ https://seturmg.wixsite.com/observatorioturismo/visitacao-em-parques-naturais $>$. Acesso em: 10 jan. 2019.

PACHECO, J. L. Interpretação do patrimônio geológico: uma aplicação ao Geoparque Arouca. 2012. 100 f. Dissertação (Mestrado em Patrimônio Geológico e Geoconservação) - Escola de Ciências, Universidade do Minho, Minho, 2012.

PÁDUA, M. T. J. Áreas de Preservação: Parques Nacionais e Reservas Biológicas. In: ENCONTRO NACIONAL CONSERVAÇÃO DA FAUNA E RECURSOS FAUNÍSTICOS, 1. 1977, Brasília. Anais... Brasília: IBDF/FBCN, 1977. p. 55-69.

PROJETO DOCES MATAS. Manual de introdução à interpretação ambiental. Belo Horizonte: IEF: IBAMA: Fundação Biodiversitas, 2002. 108p. Disponível em: $<$ http://www.ief.mg.gov.br/index.php?Hemid=58\&id=79\&option=com_conteent\&task=view $>$. Acesso em: 21 out. 2011.

RODRIGUES, J. C. Geoturismo - uma abordagem emergente. In: CARVALHO, C. N.; JACINTO, A. (Eds.). Geoturismo \& desenvolvimento local. Idanha-a-Nova: [s.1], 2008. p. 38-58.

SAADI, A. Ensaio sobre a morfotectônica de Minas Gerais. 1991. 285 f. Tese (Professor Titular)

- Instituto de Geociências, Universidade Federal de Minas Gerais, Belo Horizonte, 1991.

SIMÕES, L.S.A. Evolução tectono-metamórfica da Nappe de Passos, sudoeste de Minas Gerais. 1995. 149 p. Tese (Doutorado em Geociências) - Universidade de São Paulo, São Paulo, 1995.

SOUZA, D. A.; RODRIGUES, S. C. Aspectos Morfoestruturais da Serra da Canastra e entorno (MG). Revista do Departamento de Geografia - USP, São Paulo, v. 27, p. 47-66, 2014. https://doi.org/10.11606/rdg.v27i0.472

TILDEN, F. Interpreting Our Heritage. EUA: University of North Carolina Press, 1957. 191p. 
UHLEIN, A.; FONSECA, M. A.; SEER, H. J.; DARDENE, M. A. Tectônica da Faixa de Dobramentos Brasília - setores sententrional e meridional. Geonomos, Belo Horizonte, v. 20, n. 2, p. 1-14, 2012.

URQUí, L. C.; MARTINEZ, J. L.; VAlSERO, J. J. D. (Ed.). Patrimonio geológico y geodiversidad: investigación, gestión y relación con lós espacios naturales protegidos. Madrid: Instituto Geológico y Minero de España, 2007. 360p.

VALADÃO, R. C. Evolução de longo-termo do relevo do Brasil Ocidental (desnudação, superfícies de aplanamento e soerguimentos crustais). 1998. 243 p. Tese (Doutorado em Geologia) - Universidade Federal da Bahia, Salvador, 1998.

VASCONCELOS, J. M. O. Educação e interpretação ambiental em unidades de conservação. Cadernos de conservação, Paraná, v. 3, n. 4, 2006. 86p.

VASCONCELOS, J. M. O. Avaliação da visitação pública e da eficiência de diferentes tipos de trilhas interpretativas no Parque Estadual do Pico do Marumbi e Reserva Natural Salto Morato - PR. 1998. 151 f. Tese (Doutorado em Ciências Florestais) - Setor de Ciências Agrárias, Universidade Federal do Paraná, Curitiba, 1998.

VASQUEZ, L. M. J. Estratégia de valorização de geossítios no Geoparque Arouca. 2010. 393 f. Dissertação (Mestrado em Patrimônio Geológico e geoconservação) - Escola de Ciências, Universidade do Minho, Braga, 2010.

VEVERKA, J. A. Interpretive Master Planning: The Essential Planning Guide for Interpretive Centers, Parks, Self-Guided Trails, Historic Sites, Zoos, Exhibits and programs. Tustin, CA: Acorn Naturalists, 1998, 82p.

VON AHN, M.; SIMON, A. L. H. Geoturismo e interpretação ambiental: análise dos Critérios técnicos e estruturais dos painéis interpretativos da Rede global de geoparques. In: Encontro Lusobrasileiro de Património Geomorfológico e Geoconservação, 3., 2019. Guimarães. Anais... Guimarães: CEGOT, 2019. p. 88-102

YUSTE, C. Geoparques, intérpretes de la historia a través del lenguaje de las piedras. 2018, 3p. Disponível em: < https://www.efeverde.com/noticias/lenguaje-piedras-geoparques/>. Acesso em: 3 jun. 2019. 